Saudi Journal of Medicine

Abbreviated Key Title: Saudi J Med ISSN 2518-3389 (Print) |ISSN 2518-3397 (Online) Scholars Middle East Publishers, Dubai, United Arab Emirates Journal homepage: http://scholarsmepub.com/sjm/

Original Research Article

\title{
Alteration of the Liver Biochemical Enzymes Following Dermal Exposure to Petroleum Motor Spirit (PMS)
}

\author{
Elechi, Udochi Alegua, B.Sc (RSU), M.Sc ${ }^{1}$, Alikor Chizindu A, MBBS, MMED, FWACP, FCNPSA ${ }^{2 *}$
}

${ }^{1}$ Ignatius Ajuru University of Education, Nigeria

${ }^{2}$ Department of Medicine, University of Port Harcourt, Nigeria

DOI: 1 10.36348/sjm.2019.v04i11.005 $\quad$ | Received: 07.11.2019| Accepted: 15.11 .2019 | Published: 30.11 .2019

*Corresponding author: Alikor Chizindu A

\section{Abstract}

The present study assessed the alteration of the liver biochemical enzymes following dermal exposure to petroleum motor spirit (pms) on 25 albino whister rats. 10 served as control while the treated had 15 albino whister rats and clustered into 3 based on the treatment scheme $(1 \mathrm{ml}, 2 \mathrm{ml}$, and $3 \mathrm{ml})$. The serum biochemical assays, body weight, and histopathology of the liver where evaluated. The study revealed the mean of $101.20 \pm 2.781$ and $111.40 \pm 2.591$ for weight before and after treatement respectively with a statistically significant $(\mathrm{t}=-20.821, \mathrm{df}=9, \mathrm{p}=<0.05)$ for control subjects. While the mean of the treated group (PMS) was $116.67 \pm 12.199$ and $110.33 \pm 11.872$ for weight before and after treatment correspondingly. The study demonstrated a statistically significant mean difference between the two different weights for pre and post treatment exposure. In analyzing the biochemical assays, the result of treatment with $1 \mathrm{ml}$ PMS showed a

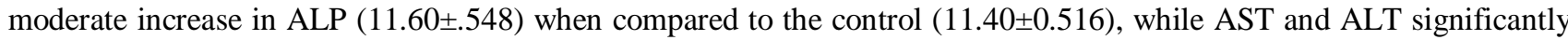
decreased $(192.00 \pm 19.170$ and $110.80 \pm 9.311)$ when compared to the control $(245.40 \pm 4.648$ and $143.60 \pm 13.426)$ at $\mathrm{P}<0.05$. When treated with $2 \mathrm{ml}$ PMS the ALP, AST, ALT (12.60 $\pm .548,298.20 \pm 29.029$ and $172.80 \pm 20.266)$ all increased when compared to the control $(11.40 \pm 0.516,245.40 \pm 4.648$ and $143.60 \pm 13.426)$ at $\mathrm{p}<0.05$. The mean comparison of the treatment of albino whister rats using 3ml PMS showed a significant increase in ALP and AST (14.00 \pm 2.739 and $275.40 \pm 30.672)$ when compared to the control $(11.40 \pm 0.516$ and $245.40 \pm 4.648)$ at $\mathrm{p}<0.05$. But, comparing the obtained result of ALT, result showed a decrease in the level of ALT (118.00 \pm 27.386$)$ when compared to control (143.60 \pm 13.426$)$. The histopathological examination results as described in the histopathology report shows significant suggestion of deformation in the cell structure of hepatocytes subsequent to treatment with varying doses of PMS. Dermal exposure of these xenobiotics is almost certainly causing morphological alterations, soreness and necrosis of the cells of the liver and spleen, as observed from the histomicrographs.

Keywords: Alteration, liver biochemical enzymes, dermal exposure, petroleum motor spirit (pms).

Copyright @ 2019: This is an open-access article distributed under the terms of the Creative Commons Attribution license which permits unrestricted use, distribution, and reproduction in any medium for non-commercial use (NonCommercial, or CC-BY-NC) provided the original author and source are credited.

\section{INTRODUCTION}

Premium Motor Spirit (PMS), also known as petrol or gasoline, is used to power internal combustion steam engines mostly in vehicles and generators. Generated from crude distillation, PMS consists of organic compounds and additives that enhance engine performance. It is a combination of volatile, flammable liquid hydrocarbons resulting from petroleum that is used as fuel for internal combustion engines. It has the potential to contain several hundred isomers of a variety of hydrocarbons. It was first produced from light naphtha batch distilled from crude oil and liquid condensate from natural gas production. Today, it is prepared through mixing various modules produced by refining procedures such as atmospheric distillation, polymerization, isomerization, and catalytic reforming amid others [1]. Petrol is distilled from crude petroleum. These fractions of crude petroleum contain aliphatic, aromatic and a variety of supplementary branched saturated and unsaturated hydrocarbon [2].

Automobile Mechanics (AM) and Petrol Station Attendants (PSA) are ordinarily found in Nigeria. The AM does schedule maintenance and repair of motor vehicles whereas the PSA dispenses PMS and other petrochemical products at automobile refueling stations. In our society, AM is commonly exposed to PMS by sucking with their mouth through a tube in an attempt to siphon PMS from the vehicle tank, this serves as a means of exposure to this compound. They also often wash vehicle parts with PMS without any gloves. PSA practice dispensing the fuel into vehicles without using any protective device to minimize their exposure. In the process, the AM and the PSA inhale 
the PMS fume. Therefore, automobile refueling and repairs are reasonable sources of benzene exposure among PSA and are in Nigeria.

This raises a serious public health concern. These classes of workers are seldom subjected to a preemployment medical examination or provided with regular medical check-ups to detect potential serious risk the exposure may have.

The chemical pollutants from petrol vapor, like another known xenobiotic, may be metabolically transformed into different metabolites in the body [3]. Some of these metabolites may be very reactive in various ways, thereby interacting in different ways with the excreting and metabolizing tissues (mainly the liver and kidneys) to elicit toxic effects ${ }^{5}$. Cellular injury may be caused by the interaction of these metabolites with the tissues, thereby, causing damage to the tissues. Some composition of petroleum products such as volatile nitrates, benzene, and lead have been reported to produce harmful effects on lymph nodes, bone marrow and spleen [4].

A population-based-cross-sectional survey carried out to investigate the potential risk of exposure to premium motor spirit (PMS) fumes in Calabar by [5], Nigeria, among Automobile Mechanics (AM), Petrol Station Attendants (PSA) and the general population. Duration of exposure was taken as the length of work in their various occupations. Venous blood was taken for methemoglobin (MetHb) and packed cells volume (PCV). Mean MetHb value was higher in AM (7.3\%) and PSA $(5.8 \%)$ than in the subjects from the general population $(2.7 \%)$. PCV was lower in PSA $(30.8 \%)$ than AM $(33.3 \%)$ and the subjects from the general population (40.8\%). MetHb level was directly proportional, and PCV inversely related, to the duration of exposure. The study suggested increased exposure to petrol fumes among AM, PSA, and MetHb as a useful biomarker in determining the level of exposure to benzene in petrol vapor.

Exposure assessment studies have indicated that significant microenvironments for benzene exposure are those associated with petrol use: driving, working at or visiting a service station, having an attachment to an automobile mechanic (AM) workshop, and living close to waste sites of petroleum refinery or chemical manufacturing plants [6]. Benzene uptake and distribution have been investigated relying on unmetabolized benzene in exhaled air (breath), blood, and urine, as well as benzene metabolites in urine among occupationally exposed workers [7]. The other method is to use blood MetHb concentration to assess exposure and for risk assessment in order to provide information on the internal dose received by individuals [8-10]
A prior study was carried out by Reese and Kimbrough, they examined acute toxicity of gasoline; and some additives. The research reported only moderately to mildly toxic at acute doses. However, due to volatility, these compounds are not extensively absorbed dermally unless the exposed skin is occluded according to [11]. After ingestion, the principal danger for a number of these chemicals, particularly gasoline, is aspiration pneumonia, which occurs mainly in children. It is currently not clear whether aspiration pneumonia would still be a problem if gasoline were diluted with ethanol or methanol. During the normal use of gasoline or mixtures of gasoline and the other solvents as a fuel, exposures would be much lower than the doses that have resulted in poisoning. No acute toxic health effects would occur during the normal course of using automotive fuels.

In a studied carried out by [12] the mortality of Tympanotonus fuscatus after acute exposure to PMS at various concentrations of $30,60,90,120$ and $150 \mathrm{ml} / \mathrm{L}$ was conducted. The study included control subjects and the acute effect of PMS was determined after 96 hours. The study suggested that PMS is very toxic.

In a study carried out by [13], they assessed the effect of RON95 gasoline on rats after 11 weeks of treatment exposure. Methodologically the study recruited a total of 16 male rats (Sprague-Dawley species) and randomly categorized into exposed and unexposed (control). The study utilized PMS vapor. Body weight was routinely confirmed and at the end of 11 weeks. The results show that gasoline inhalation was associated with a significant reduction in the rate of weight gain. The study showed that 11 weeks of exposure to PMS caused adverse effects on weight gain. The study indicates that 11 weeks of exposure to PMS was associated with some significant alterations. This study was limited to few hematological indices and in bone marrow megakaryocytes and administration route was via inhalation.

\section{MATERIALS AND METHOD Biochemical assay Alanine aminotransferase (alt)}

ALT is found in kidney, heart, muscle and greater concentration in the liver compared with other tissues of the body. ALT is purely cytoplasmic catalyzing the transamination reaction, normal serum ALT is 7-56 U/ L [14]. Any type of liver cell injury can reasonably increase ALT levels. Elevated values up to $300 \mathrm{U} / \mathrm{L}$ are considered nonspecific. Marked elevations of ALT levels greater than $500 \mathrm{U} / \mathrm{L}$ observed most often in persons with diseases that affect primarily hepatocytes such as viral hepatitis, ischemic liver injury (shock liver) and toxin-induced liver damage [15].

\section{ASPARTATE AMINOTRANSFERASE (AST)}

AST catalyze transamination reaction. AST exist in two different isoenzyme forms which are 
genetically distinct, the mitochondrial and cytoplasmic form. AST is found in highest concentration in the heart compared with other tissues of the body such as liver, skeletal muscle, and kidney [16]. Normal serum AST is 0 to 35U/L. Elevated mitochondrial AST has seen in extensive tissue necrosis during myocardial infarction and also in chronic liver diseases like liver tissue degeneration and necrosis.

\section{Animal protocol}

25 Albino whister rats $s$ weighing between $99 \mathrm{~g}$ to $125 \mathrm{~g}$ was obtained from the Biochemistry animal farm of the University of Port Harcourt and transferred to the animal unit of the Chemistry Research Laboratory, Ignatius Ajuru University of Education Rumuolumeni, Port Harcourt, and Rivers State, Nigeria.

The Albino whister rats were housed in cages (metal cages) as this follows the revised EU Directive 86/609/EEC/Annex II, on Guidelines for Accommodation and Care of Laboratory Animals. They were fed with standard rodent feed and water ad libitum and maintained under well-ventilated condition [17]. The Albino more whist rat was allowed to acclimatize to the new laboratory condition for 5 days before treatment commenced.

The Albino whister rats were separated into two groups which include Control and test groups. The test group was made up of petroleum motor spirit, which had 15 Albino whister rats, while the control had 10 rats. The test group was further divided into three sub-groups following the research design and dosage. The exposed group received sub-lethal dose $(1 \mathrm{ml}, 2 \mathrm{ml}$, and $3 \mathrm{ml}$ ) of PMS respectively by topical skin application on $2 \mathrm{~cm}$ in the shaved portion of the dorsal skin while the control groups were not treated. This treatment was repeated every 24 hours throughout the duration of the study. The study lasted for fourteen (14) days. All the Albino whister rats $s$ s were examined daily for physical and behavioral changes. The investigation was carried out based on approved institutional guidelines for the care and handling of laboratory animals as stipulated by the National and institutional guidelines for the protection of animal welfare during experiments

\section{Sample collection}

At the end of the study, the albino whister rats (designated as treated and Control), their weight was determined, anesthetized, sacrificed and their blood collected by cardiac puncture using uncontaminated syringe and needle. The blood was carefully transmitted into an EDTA bottle and left at room temperature to clot. Afterward, they were centrifuged at $4000 \mathrm{rpm}$ for 5 minutes. Separated Serum was carefully transferred into fresh clean dry bottles and stored at $50^{\circ} \mathrm{c}$ for enzyme assay.

Afterward, the rats were further dissected and their liver carefully excised, cleaned of any attached strands and stored in a plain sample bottled filled with formalin for histopathology.

\section{Histopathology investigation}

A portion of the excised rat liver and spleen was fixed in $10 \%$ formalin, washed, dehydrated in isopropanol, rinsed with xylene and embedded in paraffin wax. The paraffin sections were prepared and stained with hematoxylin and eosin. Thin sections of the liver were made into permanent slides and examined under a microscope with photographic facility and photomicrographs were taken. The micrographs were analyzed and interpreted by the pathologist. The processing, sectioning, staining, microscopic examination, and interpretation were carried out as described by [18].

\section{DATA ANALYSIS}

Results from the investigation will be expressed as the mean of triplicate determinations \pm standard deviation. Comparison between treated and corresponding control was made using SPSS Statistical Package for Social Sciences (SPSS) version 20. Group means were compared for significance at $p \leq 0.05$. Data were represented as the mean \pm standard deviation for $\mathrm{t}$ test of equal variants to determine the "p" value. A "p" value $<0.05$ was considered statistically significant.

\section{RESULTS AND DISCUSSION Mean Weight Comparison}

Mean weight comparison was established using a paired sample t-test for weight before and after. The study revealed the mean of $101.20 \pm 2.781$ and $111.40 \pm 2.591$ for weight before and after respectively with a statistically significant $(\mathrm{t}=-20.821, \mathrm{df}=9$, $\mathrm{p}=<0.05$ ) for control subjects. See table 4.1 for details.

Table-1.1: Paired Samples Test for Control Weight Before and Weight After

\begin{tabular}{|l|l|l|l|l|l|}
\hline & Mean \pm SD & t-test & Df & p-value & Remark \\
\hline Weight Before Control & $101.20 \pm 2.781$ & -20.821 & 9 & $<0.05$ & Sig \\
\hline Weight After Control & $111.40 \pm 2.591$ & & & & \\
\hline
\end{tabular}

Table 4.2 further presents a paired t-test distribution for PMS exposed albino whister rats $s$ with the following means; $116.67 \pm 12.199$ and
$110.33 \pm 11.872$ for weight before and after correspondingly. The study demonstrated a statistically significant mean difference between the two different 
weights for pre and post treatment exposure. These invariable shows that the exposure to PMS affected the weight of the experimental animal.

Table-1.2: Paired Samples Test for Weight before and Weight after for PMS Exposed Rat

\begin{tabular}{|l|c|l|l|l|l|}
\hline & Mean \pm SD & t-test & Df & p-value & Remark \\
\hline Weight Before PMS & $116.67 \pm 12.199$ & 2.391 & 14 & 0.03 & Sig \\
\hline Weight After PMS & $110.33 \pm 11.872$ & & & & \\
\hline
\end{tabular}

Sig $=$ Significant $=p<0.05 ; N / S=$ Not Significant $=p>0.05$.

\section{PMS Mean Comparison}

Table-1.3: ANOVA of Control and Treatment Doses (1ml, 2ml \&3ml) of PMS

\begin{tabular}{|l|c|c|c|c|c|c|c|c|}
\hline Variables & $\begin{array}{c}\text { Control } \\
(\mathbf{N = 1 0})\end{array}$ & $\boldsymbol{P M S 1}(\mathbf{N = 5 )}$ & $\boldsymbol{P M S 2}(\mathbf{N = 5 )}$ & $\boldsymbol{P M S 3}(\mathbf{N = 5 )}$ & $\begin{array}{c}\boldsymbol{F} \text { - } \\
\text { value }\end{array}$ & $\begin{array}{c}\boldsymbol{d} \text { - } \\
\text { value }\end{array}$ & Remark \\
\hline ALP & $11.40 \pm 0.516$ & $11.60 \pm .548$ & $12.60 \pm .548$ & $14.00 \pm 2.739$ & 5.068 & 24 & 0.01 & $\mathrm{Sig}$ \\
\hline AST & $245.40 \pm 4.648$ & $192.00 \pm 19.170$ & $298.20 \pm 29.029$ & $275.40 \pm 30.672$ & 25.327 & 24 & $<0.05$ & $\mathrm{Sig}$ \\
\hline ALT & $143.60 \pm 13.426$ & $110.80 \pm 9.311$ & $172.80 \pm 20.266$ & $118.00 \pm 27.386$ & 12.775 & 24 & $<0.05$ & $\mathrm{Sig}$ \\
\hline AST/ALT & $1.720 \pm .1333$ & $1.731 \pm .0267$ & $1.728 \pm .0333$ & $2.504 \pm .91909$ & $<0.050$ & 24 & 1.00 & $\mathrm{~N} / \mathrm{S}$ \\
\hline ALT/ALP & $12.67 \pm 1.721$ & $9.60 \pm 1.278$ & $13.79 \pm 2.243$ & $8.37 \pm .3423$ & 13.898 & 24 & $<0.05$ & $\mathrm{Sig}$ \\
\hline
\end{tabular}

Table-1.4: Mean Comparison of Control and Treatment Dose of 1ml (PMS)

\begin{tabular}{|l|c|c|l|l|l|l|}
\hline Variables & Control $(\mathbf{N = 1 0})$ & PMS1 $(\mathbf{N = 5 )}$ & F-value & Df & p-value & Remark \\
\hline ALP & $11.40 \pm 0.516$ & $11.60 \pm .548$ & 57.178 & 14 & $<0.05$ & Sig \\
\hline AST & $245.40 \pm 4.648$ & $192.00 \pm 19.170$ & 19.376 & 14 & $<0.05$ & Sig \\
\hline ALT & $143.60 \pm 13.426$ & $110.80 \pm 9.311$ & 20.038 & 14 & $<0.05$ & Sig \\
\hline AST/ALT & $1.720 \pm .1333$ & $1.731 \pm .0267$ & $<0.050$ & 14 & 1.00 & N/S \\
\hline ALT/ALP & $12.67 \pm 1.721$ & $9.60 \pm 1.278$ & $<0.050$ & 14 & 1.00 & N/S \\
\hline
\end{tabular}

The result of treatment with $1 \mathrm{ml}$ PMS showed a moderate increase in ALP (11.60土.548) when compared to the control (11.40 \pm 0.516$)$, while AST and
ALT significantly decreased $(192.00 \pm 19.170$ and $110.80 \pm 9.311)$ when compared to the control $(245.40 \pm 4.648$ and $143.60 \pm 13.426)$ at $\mathrm{P}<0.05$

Table-1.5: Mean Comparison of Control and Treatment Dose of 2ml (PMS)

\begin{tabular}{|l|c|c|c|c|c|c|}
\hline Variables & Control $(\mathbf{N = 1 0})$ & PMS2 $(\mathbf{N = 5})$ & F-value & Df & p-value & Remark \\
\hline ALP & $11.40 \pm 0.516$ & $12.60 \pm .548$ & 8.658 & 14 & $<0.05$ & Sig \\
\hline AST & $245.40 \pm 4.648$ & $298.20 \pm 29.029$ & 336.499 & 14 & $<0.05$ & Sig \\
\hline ALT & $143.60 \pm 13.426$ & $172.80 \pm 20.266$ & 45.324 & 14 & $<0.05$ & Sig \\
\hline AST/ALT & $1.720 \pm .1333$ & $1.728 \pm .0333$ & 1.00 & 14 & $<0.05$ & N/S \\
\hline ALT/ALP & $12.67 \pm 1.721$ & $13.79 \pm 2.243$ & 26.462 & 14 & $<0.05$ & Sig \\
\hline
\end{tabular}

The table shows that when the albino whister rats were treated with $2 \mathrm{ml}$ PMS the ALP, AST, ALT $(12.60 \pm .548, \quad 298.20 \pm 29.029$ and $172.80 \pm 20.266)$ increased when compared to the control $(11.40 \pm 0.516$, $245.40 \pm 4.648$ and $143.60 \pm 13.426)$ at $\mathrm{p}<0.05$.

Table-4.6: Mean Comparison of Control and Treatment Dose of 3ml PMS

\begin{tabular}{|l|c|c|c|c|c|c|}
\hline Variables & Control $(\mathbf{N = 1 0})$ & $\boldsymbol{P M S 3}(\mathbf{N}=5)$ & F-value & $\boldsymbol{D} \boldsymbol{p}$ & $\boldsymbol{p}$-value & Remark \\
\hline ALP & $11.40 \pm 0.516$ & $14.00 \pm 2.739$ & 4.505 & 14 & $<0.05$ & Sig \\
\hline AST & $245.40 \pm 4.648$ & $275.40 \pm 30.672$ & 431.076 & 14 & $<0.05$ & Sig \\
\hline ALT & $143.60 \pm 13.426$ & $118.00 \pm 27.386$ & 24.045 & 14 & $<0.05$ & Sig \\
\hline AST/ALT & $1.720 \pm .1333$ & $2.504 \pm .91909$ & $<0.050$ & 14 & 1.00 & N/S \\
\hline ALT/ALP & $12.67 \pm 1.721$ & $8.37 \pm .3423$ & 9.957 & 14 & $<0.05$ & Sig \\
\hline
\end{tabular}

The mean comparison of the treatment of albino whister rats using $3 \mathrm{ml}$ PMS showed a significant increase in ALP and AST (14.00 \pm 2.739 and $275.40 \pm 30.672)$ when compared to the control
$(11.40 \pm 0.516$ and $245.40 \pm 4.648)$ at $\mathrm{p}<0.05$. But, comparing the obtained result of ALT, result showed a decrease in the level of ALT (118.00 \pm 27.386$)$ when compared to control (143.60 \pm 13.426$)$. 


\section{Histopathological report of exposed group (pms)}

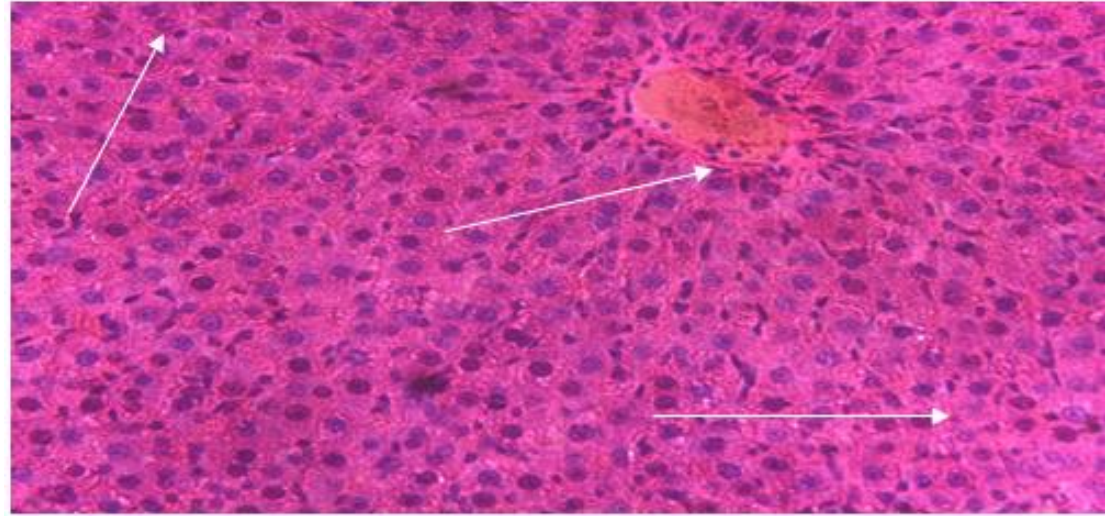

Fig-01a: Slide Section of Liver Treated with $1 \mathrm{ml}$ PMS

Histological section of the liver shows micro tissue proliferation with few inflammatory cells infiltrates. The central vein appears normal but the sinusoids and the lamina are not clearly identified.

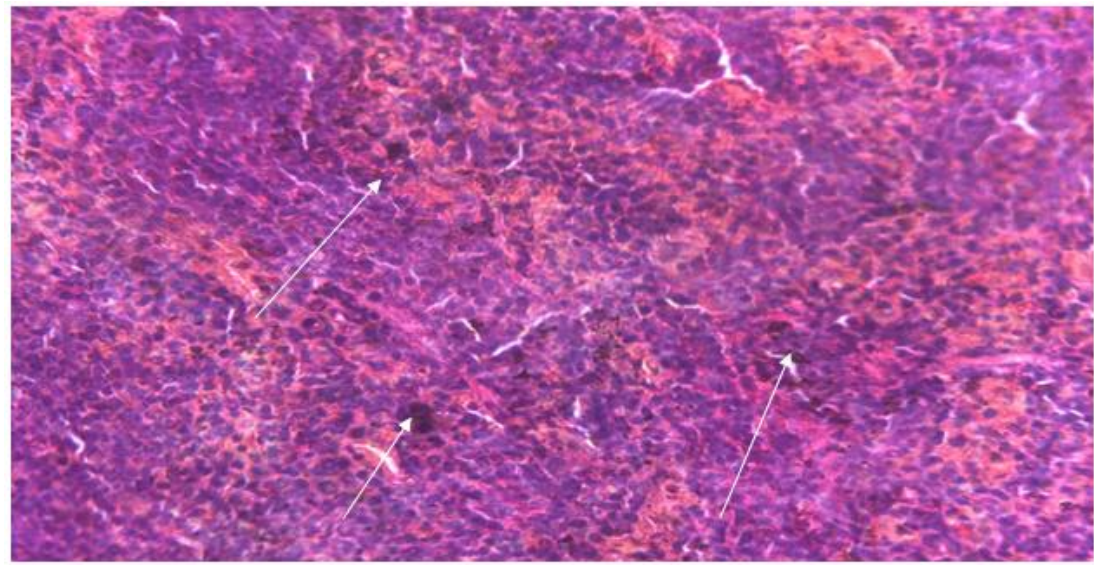

Fig-1b: Slide Section of Liver Treated with $2 \mathrm{ml}$ PMS

The histological section shows liver tissue with unremarkable central vein, proliferation, marked cellularity around the central vein and inflammatory cells infiltrates the sinusoids. The lamina is equally distorted. The hepatocytes are of varying sizes. There are some cystically related spaces within the stroma.

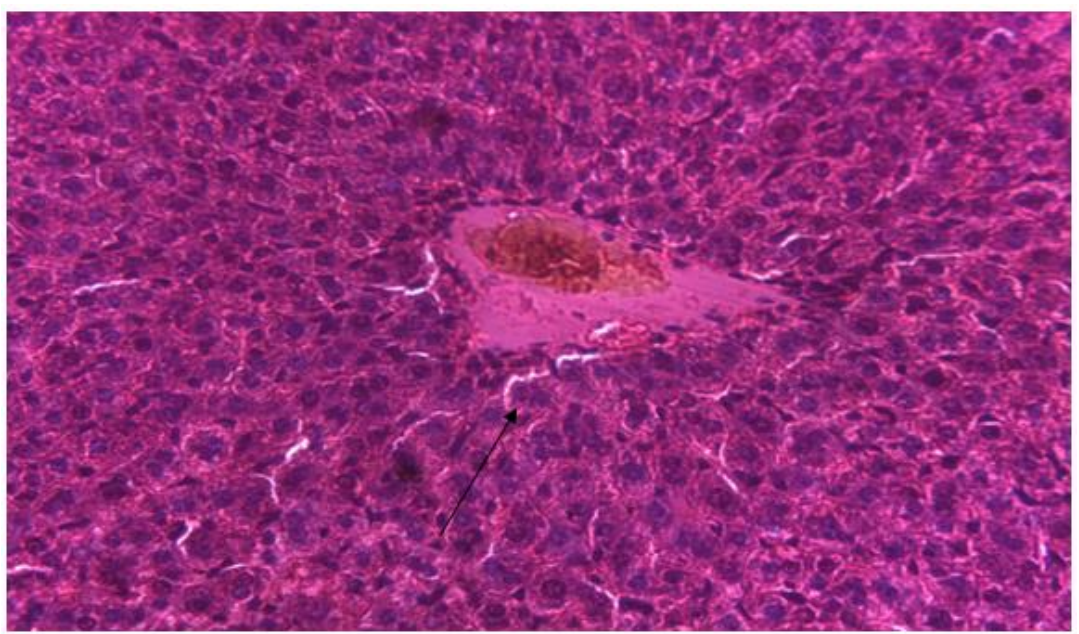

Fig-1c: Slide Section of Liver Treated 3ml PMS

The histological section shows liver tissues with proliferation; poorly arranged sinusoids and lamina, inflammatory cells, slightly enlarged central vein and dense stroma. The hepatocytes appear unremarkable. 


\section{Summary of histopathological report}

The histopathological examination results as described above shows the suggestion of deformation in the cell structure of hepatocytes subsequent to treatment with varying doses of PMS. Dermal exposure of these xenobiotics is almost certainly causing morphological alterations, soreness, and necrosis of the cells of the liver, as observed from the photomicrographs. Chronic dermal exposure to PMS had resulted in the absorption of its components into the bloodstream and subsequent uptake by the liver. This has been shown to induce damaging effects on hepatocytes causing hepatotoxicity.

\section{DISCUSSION}

In this study, the liver function tests were assessed since the liver is considered as one of the primary organs of detoxification and various experimental and animal studies have also shown that the organic solvents used in petrol chemical industries affect the hepatic functions adversely.

In this study, although the mean values of SAST, SASP, SALP were observed within their respective reference ranges, still these enzymes were found significantly higher among the albino whister rats group treated with PMS in comparison to the control group. This in effect showed that as the dose increased, the three was significant increase in the effect and alteration of the biochemical enzyme activities. This alteration was more when the rats were treated with $2 \mathrm{ml}$ PMS.

However, the observations regarding the liver functions in the present study were in contrast to the findings of [19] which did not reveal any difference in the levels of liver enzymes in both PMS attendants and the controls except for significantly lower levels of Alkaline Phosphatase. Such difference in the findings of various research work, are quite probable and might be due to the variations in the period and concentrations to which they are exposed, methodology adopted, differences in conduct of the potential confounding factors such as age, sex.

The possible metabolic mechanisms for the underlying alterations in the liver enzymes as proposed by the various investigators worldwide are that following inhalation, benzene and the other hydrocarbons present in gasoline are readily absorbed from the lungs and get metabolized in the liver by CYP450 2E1 oxidative pathways which contribute to the production of free radicals and quinine metabolites such as phenol, hydroquinone, benzoquinone; 1,2,4 benzenetriol. These free radicals and toxic metabolites cause lipid peroxidation and damage of hepatic cell membrane, causing the release of liver enzymes in the circulation [20]. As this study was limited to a small sample size, so it would be premature to generalize the results of this study to the entire population of PMS usuers; however, it cannot be also denied that the outcomes of the usuage of OMS for any reason become apparent after a number of years. Thus, it is imperative to recognize the possible dangers early and take important measures before they result into permanent morbidities [21].

Furthermore, the research on the concept of bio-diesel, which is still in its infancy, should be explored, as it may serve as a boon to cope with the adverse effects of the noxious chemical constituents of gasoline vapors in the near future

\section{CONCLUSION}

PMS were introduced into the body system of the Albino rats through dermal route. The obtained results indicate that changes induced by PMS hydrocarbon alter the activities of the liver and spleen. From the results obtained in course of the experiment carried out, it is apparent that PMS alters the following parameters to a significant level: body weight, Alanine aminotransferase (ALT), Aspartate Amino Transferase (AST), Alkaline Phosphatase (ALP), AST/ALT ratio and ALT/ALP ratio. PMS however, demonstrated slight genotoxicity as well as systemic toxicity to the liver and the serum. Therefore, the study shows dose-related alteration toxicity on rodents such as albino rats.

From the above, it may be concluded that such biochemical changes as observed in the experimental animals may likely occur in humans. It is important that humans avoid any form of exposure to these samples.

\section{REFERENCES}

1. Mauro, P., Renze, B., Wouter, W. (2006). In: Tietz text book of clinical chemistry and molecular diagnostics. 4th edition. Carl AB, Edward R, David EB, editors. Elsevier. Enzymes. 604-616.

2. Anderson, D., Yu, T.W., Schmezer, P. (1995). An investigation of the DNA-damaging ability of benzene and its metabolites in human lymphocytes, using the comet assay. Environmental and molecular mutagenesis, 26(4):305-14.

3. Diana, N.C. (2007). Appendix: Therapeutic drug monitoring and laboratory reference ranges. Current medical diagnosis and treatment. Stephen JM, Maxine AP. 46th edition, Mc Graw hill, 176775.

4. Rosalki, S.B, Mcintyre, N. (1999). 2nd ed. New York: Oxford university press. Biochemical investigations in the management of liver disease. Oxford textbook of clinical hepatology, 503-521.

5. Udonwa, N.E., Uko, E.K., Ikpeme, B.M., Ibanga, I.A., Okon, B.O. (2009). Exposure of petrol station attendants and auto mechanics to premium motor sprit fumes in Calabar, Nigeria. Journal of Environmental and Public Health, 2009.

6. Wallace, L. (1996). Environmental exposure to benzene: an update. Environmental health perspectives. 1996 Dec, 104(suppl 6):1129-36. 
7. Hayes, R.B., Dosemeci, M., Wacholder, S., Travis, L.B., Rothman, N., Hoover, R.N., Linet, M.S., Yin, S.N., Li, G.L., Li, C.Y.(1997). Benzene and the dose-related incidence of hematologic neoplasms in China. Journal of the National Cancer Institute, Jul 16;89(14):1065-71.

8. Hotz, P., Carbonnelle, P., Haufroid, V., Tschopp, A., Buchet, J. P., \& Lauwerys, R. (1997). Biological monitoring of vehicle mechanics and other workers exposed to low concentrations of benzene. International Archives of Occupational and Environmental Health, 70(1), 29-40.

9. Nwanjo, S.U., \& Ojiako T.M. (2001). Biochemical changes in the plasma and liver of albino rats exposed to petroleum models (gasoline, kerosene and crude oil). J.Appl. Sci. Environ. Mgt, 5(1): 97100.

10. Parkinson, G. S. (1971). Benzene in motor gasoline - an investigation into possible health hazards in and around filling stations and in normal transport operations. Annals of Occupational Hygiene, 14(2), 145-153.

11. Ayalogu, O. E., Igboh, N. M., \& Dede, E. B. (2001). Biochemical Changes in the Serum and Liver of albino rats exposed to Petroleum Samples (gasoline, kerosene, and crude Petroleum). Journal of Applied Sciences and Environmental Management, 5(1).

12. Edori, O. S., Edori, E. S., \& Iyama, W. A. (2015). Effect of Premium Motor Spirit (Petrol) on Lethality of Tympanotonus Fuscatus after Acute Exposure.

13. Abubakar, M. B., AbdullAh, W. Z., Sulaiman, S. A., \& Ang, B. S. (2015). The effects of exposure to petrol vapours on growth, haematological parameters and oxidative markers in spraguedawley male rats. The Malaysian journal of medical sciences: $M J M S, 22(1), 23$.

14. Diana Nicoll, C. (2007). Appendix: Therapeutic drug monitoring and laboratory reference ranges. Current medical diagnosis and treatment. Stephen JM, Maxine AP. 46th edition, Mc Graw hill, 1767-1775.

15. Rosalki, S.B., Mcintyre, N. (1999). 2nd ed. New York: Oxford university press. Biochemical investigations in the management of liver disease. Oxford textbook of clinical hepatology, 503-521.

16. Giannini, E., Risso, D., Botta, F., Chiarbonello, B., Fasoli, A., Malfatti, F., \& Testa, R. (2003). Validity and clinical utility of the aspartate aminotransferase-alanine aminotransferase ratio in assessing disease severity and prognosis in patients with hepatitis $\mathrm{C}$ virus-related chronic liver disease. Archives of internal medicine, 163(2), 218224.

17. Giannini, E., Botta, F., Fasoli, A., Ceppa, P., Risso, D., Lantieri, P. B., \& Testa, R. (1999). Progressive liver functional impairment is associated with an increase in AST/ALT ratio. Digestive diseases and sciences, 44(6), 1249-1253.

18. Giannini, E., Botta, F., Fasoli, A., Romagnoli, P., Mastracci, L., Ceppa, P., \& Testa, R. (2001). Increased levels of $\gamma \mathrm{GT}$ suggest the presence of bile duct lesions in patients with chronic hepatitis C. Digestive diseases and sciences, 46(3), 524-529.

19. Khan, S., Irfan, M., \& Rahimtula, A. D. (1987). The hepatotoxic potential of a Prudhoe Bay crude oil: effect on mouse liver weight and composition. Toxicology, 46(1), 95-105.

20. Sell, S. (2008). Alpha-fetoprotein, stem cells and cancer: how study of the production of alphafetoprotein during chemical hepatocarcinogenesis led to reaffirmation of the stem cell theory of cancer. Tumor Biology, 29(3), 161-180.

21. Smith, G. C., Wood, A. M., Pell, J. P., White, I. R., Crossley, J. A., \& Dobbie, R. (2004). Secondtrimester maternal serum levels of alphafetoprotein and the subsequent risk of sudden infant death syndrome. New England Journal of Medicine, 351(10), 978-986. 